\title{
HUBUNGAN ANTARA KEBIASAAN BELAJAR DENGAN HASIL BELAJAR SISTEM PENGAPIAN
}

\author{
Sekar A. Ningtyas ${ }^{1}$, Wowo S. Kuswana ${ }^{2}$, Tatang Permana ${ }^{3}$ \\ Departemen Pendidikan Teknik Mesin \\ Universitas Pendidikan Indonesia \\ Jl. Dr. Setiabudhi No. 207 Bandung 40154 \\ sekararum.ningtyas@yahoo.co.id
}

\begin{abstract}
ABSTRAK
Tujuan penelitian ini untuk mecari besar hubungan antara kebiasaan belajar dengan hasil belajar siswa SMK. Metode penelitian yang digunakan adalah metode korelasional. Sampel menggunakan teknik purposive sampling dengan jumlah sampel sebanyak 55 orang siswa. Instrumen penelitian menggunakan kuesioner tertutup berdasarkan skala Likert. Pengujian validitas instrumennya menggunakan expert judgement. Penelitian difokuskan pada kebiasaan belajar, meliputi: kebiasaan gerak, kebiasaan verbal, kebiasaan sosial, kebiasaan moral, dan kebiasaan cara berpikir ilmiah. Hasil penelitian menunjukkan bahwa kebiasaan belajar siswa SMK mayoritas memiliki kebiasaan belajar gerak. Hasil belajar siswa tergolong pada kategori sedang atau cukup baik. Hubungan antara kedua variabel menunjukkan positif dan signifikan antara kebiasaan belajar dengan hasil belajar siswa dengan nilai koefisien korelasi 0,9. Kesimpulan penelitian ini bahwa hubungan antara kebiasaan belajar siswa dengan hasil belajar sangat kuat.
\end{abstract}

Kata kunci: kebiasaan, gerak, verbal, sosial, moral, pengapian

\begin{abstract}
The method used was a descriptive correlational method. Sampling technique using simple random sampling technique in order to get a total sample of 55 students. The research instrument used was a questionnaire form enclosed questionnaire which is based on a Likert scale. Testing instrument validity using expert judgment. The focus of the research mentioned that the habit of movement, verbal habits, social habits, moral habits, and habits of scientific thinking. The studies show that majority has a habit of studying movement. Student learning outcomes classified into categories of moderate or good enough. There is a positive and significant relationship between study habits with student learning outcomes. Correlation value coefficient study habits to learning outcomes are 0.9 . The conclutions is the relationship between study habits of students with learning outcomes is very strong.
\end{abstract}

Keywords: habits, movement, verbal, social, attitude, ignition

\footnotetext{
${ }^{1}$ Mahasiswa Departemen Pendidikan Teknik Mesin FPTK UPI

${ }^{2}$ Dosen Departemen Pendidikan Teknik Mesin FPTK UPI

${ }^{3}$ Dosen Departemen Pendidikan Teknik Mesin FPTK UPI
} 


\section{PENDAHULUAN}

Sekolah Menengah Kejuruan atau SMK adalah bagian terpadu dari Sistem Pendidikan Nasional, yang mempunyai peranan penting didalam menyiapkan dan pengembangan SDM. Lulusan SMK diharapkan mampu memenuhi tantangan berwirausaha maupun menjadi lulusan yang siap kerja. Siswa diharapkan mampu mengusai standar kompetensi yang telah ditetapkan sehingga dapat menjadi calon lulusan yang siap kerja, terampil, dan kompeten. SMK yang dijadikan objek penelitian oleh penulis adalah SMK MedikaCom. SMK MedikaCom adalah salah satu sekolah kejuruan yang memiliki akreditasi A dan berstandar ISO 9001:2000. Lulusan dari SMK MedikaCom ini diharapkan mampu menjadi lulusan yang siap kerja, mampu berwirausaha, dan mahir dalam kompetensi pilihannya. Program keahlian Teknik Sepeda Motor, Teknik Kendaraan Ringan, dan Teknik Pemesinan memiliki bengkel yang dilengkapi dengan sarana yang cukup memadai. Siswa diminta untuk mengenakan wearpack dan membawa lembar jobsheet dalam setiap praktikum, hal ini bertujuan agar pekerjaan yang harus dilakukan siswa lebih terarah dan dapat melakukan pekerjaan sesuai dengan SOP (Standard Operational Procedure).

Setiap siswa kelas XII akan dihadapkan pada kegiatan Praktik Kerja Lapangan (PKL). Hal ini didasarkan pada tujuan sekolah untuk mencetak lulusan yang mahir dan siap kerja. Sebelum siswa menghadapi PKL. Tentunya siswa diberikan pembekalan berupa teori dan praktik di sekolah di kelas XI. Harapan sekolah tentunya agar siswa sudah siap dan percaya diri menghadapi PKL dan mampu mendapatkan hasil belajar yang baik agar mengharumkan nama sekolah. Kenyataan yang terjadi adalah tidak semua siswa dapat memahami pembelajaran dengan baik dan hasil belajar siswa pun tak semua memenuhi Standar Ketuntasan Minimal (SKM).

Masih besar prosentase siswa yang tidak lulus pada kompetensi Sistem Pengapian. Hal ini mengindikasikan perlu adanya perhatian khusus dari para guru TSM kelas XI khususnya pada mata pelajaran Sistem Pengapian. Setiap siswa perlu mendapat perhatian yang tepat sasaran dan baik, sehingga berakhir dengan hasil yang memuaskan. Perlu adanya penelitian yang dapat menentukan metode pembelajaran untuk siswa tersebut pada proses pembelajaran produktif untuk menghasilkan SDM yang terbaik dalam dunia kerja.

Sebelum melaksanakan metode tertentu, setiap pengajar perlu mengetahui metode yang tepat untuk diberi perlakuan pada kelas. Kemampuan setiap siswa antara satu dengan yang 
lainnya di dalam kelas sangatlah berbeda. Sehingga diperlukan strategi perilaku awal kepada siswa dalam proses pembelajaran. Perilaku awal adalah perilaku yang diperoleh siswa sebelum ia memperoleh perilaku yang baru. Salah satu perilaku awal yang akan digunakan untuk menentukan strategi belajar adalah kebiasaan belajar.

Siswa seringkali belum menyadari dan memahami mengenai kebiasaan belajarnya sendiri. Mereka berpandangan bahwa kebiasaan belajar yang baik hanya berupa rajin membaca buku dan memperhatikan ketika guru menjelaskan di depan kelas, serta aktif dalam aktifitas diskusi. Namun sesungguhnya kebiasaan belajar itu merupakan dasar. Hal-hal yang sering mereka lakukan secara berulang-ulang tanpa mereka sadari sehingga menjadi suatu kebiasan. Inilah yang mendasari setiap perilaku mereka dalam proses pembelajaran yang kemudian menjadi acuan guru untuk menentukkan strategi belajar apa yang tepat digunakan di dalam kelas.

Penentuan strategi belajar yang cocok dengan kebiasaan belajar tentunya dilakukan dengan pendekatan empiris yang harus terus menerus diuji ketepatannya. Kemampuan untuk mengembangkan strategi belajar yang efektif untuk siswa yang sesuai dengan kebiasaan belajar orang tersebut (Riyanto, 2010). Tentunya sangat membantu siswa dalam mencapai hasil belajar yang lebih baik. Mengenali kebiasaan belajar dapat menentukan dan mengetahui bagaimana memanfaatkan kemampuan belajar secara maksimal, sehingga hasil belajarnya menjadi lebih optimal.

Agar tujuan di atas dapat tercapai, kegiatan proses belajar mengajar perlu adanya berbagai tindakan antara siswa dan pengajar yang dapat meningkatkan kualitas lebih baik dalam kegiatan belajar mengajar (Sanjaya, 2011). Salah satunya dengan mengetahui kebiasaan belajar siswa ketika belajar dan menumbuhkan semangat belajar siswa. Studi tentang kebiasaan belajar dan strategi belajar telah banyak dilakukan dan selalu menarik perhatian mengingat perannya yang penting dalam pencapaian hasil belajar. Kebiasaan belajar siswa (Hughes and Hughes, 2012) beragam jenis dari kebiasaan, yaitu: gerak, verbal, sosial, moral dan cara berpikir ilmiah.

\section{METODE PENELITIAN}

Metode penelitian yang digunakan dalam penelitian ini adalah metode korelasi. Metode ini digunakan untuk mengemukakan ada atau tidaknya hubungan. Sseberapa erat dan berartinya hubungan tersebut serta yang dapat diambil. Variabel penelitian ini yaitu: variabel 
kebiasaan belajar dan hasil belajar. Populasi dalam penelitian ini adalah seluruh siswa kelas XI Program Teknik Otomotif SMK MedikaCom Bandung, yang terbagi menjadi dua program keahlian yaitu Teknik Kendaraan Ringan dan Teknik Sepeda Motor. Sampel digunakan yaitu teknik purposive sampling. Sampel dalam penelitian ini adalah siswa kelas XI TSM di SMK MedikaCom Bandung dengan jumlah 55 siswa.

\section{HASIL PENELITIAN}

Pengambilan telah dilakukan pada sampel yang berjumlah 55 siswa. Hasil analisis data diperoleh dari variabel kebiasaan belajar sebagai berikut: gerak 58,2\%, verbal 38,5\%, sosial 14,5\%, moral 14,5\% dan kebiasaan cara berpikir ilmiah sebesar 5,4\%. Hasil uji kecenderungan variabel hasil belajar yang dilakukan pada sampel siswa dapat dilihat pada Tabel 1.

Tabel 1. Kecenderungan hasil belajar

\begin{tabular}{lcc}
\hline \multicolumn{1}{c}{ Kategori } & Frekuensi & Persentase \\
\hline Sangat Tinggi & 3 & 5.5 \\
Tinggi & 14 & 25.5 \\
Sedang & 24 & 45.5 \\
Rendah & 9 & 15.4 \\
Sangat Rendah & 5 & 9.1 \\
Jumlah & 55 & 100 \\
\hline
\end{tabular}

\section{PEMBAHASAN}

Setiap siswa pastilah memiliki sekurang-kurangnya satu kebiasaan belajar. Adapun siswa yang memiliki lebih dari satu kebiasaan belajar dan dua-duanya kuat. Siswa banyak yang memiliki kebiasaan belajar gerak karena berada dalam lingkungan sekolah vokasi yang sering melaksanakan praktikum di bengkel. Kebiasaan gerak melewati beberapa tahap, yaitu kerapian, kehalusan, dan kemudahan (Hughes and Hughes, 2012). Praktikum yang dilaksanakan di bengkel sekolah, mengajarkan siswa untuk dapat melakukan pekerjaan yang dilampirkan pada jobsheet dengan benar dan cermat. Hal inilah yang kemudian mendorong siswa untuk membiasakan kebiasaan gerak pada dirinya. 
Gerakan yang dilakukan siswa mulanya terpatah-patah karena masih dalam tahap pengenalan komponen. Setelah berhasil melakukan pekerjaannya, lalu dipertemuan selanjutnya gerakan siswa menjadi lebih rapi, lebih halus, dan mudah, sehingga dengan sendirinya siswa dapat menyelesaikan pekerjaan dengan baik karena sudah terbiasa. Mata pelajaran Sistem Pengapian adalah kelompok mata pelajaran produktif otomotif untuk kelas XI Teknik Sepeda Motor yang diberikan di semester ganjil. Sistem Pengapian membekali siswa dengan materi; fungsi Sistem Pengapian, pengenalan komponen dan fungsi komponen Sistem Pengapian konvensional, konstruksi dan rangkaian Sistem Pengapian konvensional, cara kerja Sistem Pengapian konvensional, pemeriksaan komponen Sistem Pengapian konvensional, perbaikan dan penggantian komponen Sistem Pengapian, dan pengujian dan penyetelan Sistem Pengapian.

Berpikir ilmiah masih sangat rendah pada siswa SMK. Hal perlu diwaspadai mengingat pekerjaan di lapangan memerlukan kemampuan ini. Oleh karena itu, proses pembelajaran harus dimasukan kemampuan dalam meningkatkan cara bepikir ilmiah siswa (Kuswana, 2011). Berpikir ilmiah merupakan satu kompetensi yang diperlukan oleh seorang teknisi sekalipun. Kemampuan ini digunakan untuk mempercepat dan mempermudah proses kerja dan hasil yang lebih memuaskan.

Data yang telah dikemukakan sebelumnya memperlihatkan bahwa, frekuensi hasil belajar terbanyak adalah 24 siswa dengan presentase sebesar $45.5 \%$, dan termasuk dalam kategori sedang. Hasil tersebut menunjukkan bahwa mayoritas siswa kelas XI TSM di SMK MedikaCom Bandung memiliki hasil belajar yang cukup baik.

\section{KESIMPULAN}

Kebiasaan belajar siswa didominasi oleh kebiasaan belajar gerak dan verbal. Hal tersebut diduga karena mata pelajaran sistem pengapian sebagian besar adalah mata pelajaran praktikum yang membutuhkan gerak (praktik untuk membongkar dan memasang) dan hapalan yang bagus dalam proses pembelajarannya. Hasil belajar siswa berkategori sedang, artinya secara keseluruhan siswa memiliki prestasi belajar masih dapat menunjang proses belajar mengajar pada mata pelajaran Sistem Pengapian. Ada hubungan yang positif, signifikan dan kuat antara kebiasaan belajar dengan hasil belajar siswa pada mata pelajaran sistem pengapian. 


\section{DAFTAR PUSTAKA}

Hughes, A.G and E.H Hughes. (2012). Learning and Teaching: Pengantar Psikologi Pembelajaran Modern. Bandung: Nuansa Cendikia.

Kuswana, W. S. (2011). Taksonomi Berpikir. Bandung: PT. Remaja Rosda Karya.

Riyanto, Y. (2010). Paradigma Baru Pembelajaran. Jakarta: Kencana Predana Media Grup.

Sanjaya, W. (2011). Pembelajaran dalam Implementasi Kurikulum Berbasis Kompetensi. Jakarta: Kencana. 